\title{
Eurozone regulation bias in the Active Share measure
}

\author{
Lidia Loban*, José Luis Sarto* and Luis Vicente ${ }^{*}, * *$ \\ * Department of Accounting and Finance. University of Zaragoza (Spain). \\ *** Corresponding author (lavicent@unizar.es)
}

This version: July 2020

\begin{abstract}
This study is the first to examine how both the domestic equity benchmark concentration and the Directive 2009/65/EC on risk of portfolio diversification may distort the accuracy of the original Active Share measure of Cremers and Petajisto (2009) in the Eurozone mutual fund industry. The main contribution of this paper is to provide statistical significance to the Active Share measure considering the spurious activity levels due to this benchmark concentration. The empirical application to a comprehensive sample of domestic equity funds provides evidence of significant differences in the actual levels of active management in the Eurozone mutual fund industries.
\end{abstract}

Keywords: active share; benchmark concentration; Eurozone mutual fund industry; portfolio regulation.

JEL codes: G11; G18; G23.

\section{Acknowledgements}

This work was funded by Ministerio de Ciencia, Innovación y Universidades (MCIU, Spanish Government), Agencia Estatal de Investigación (AEI), Fondo Europeo de Desarrollo Regional (FEDER) [RTI2018-093483-B-I00]; and Gobierno de Aragón [CIBER S38_17R].

Lidia Lobán thanks the specific support provided by Ministerio de Ciencia, Innovación y Universidades (MCIU, Spanish Government) [FPU16/03779].

We really thank all the insightful comments and suggestions of an anonymous reviewer. 


\section{Introduction}

Today's investors are increasingly interested in mutual fund selection, thereby demanding detailed information and investment advice. One of the most extensive debates in mutual funds is concerned with the efficiency of actively managed mutual funds, as they are a major component of this industry ${ }^{1}$.

Mutual funds are an important financial institution in the global markets. In Q4 2018, the Total Net Assets (TNA) of worldwide-regulated open-end fund assets were $€ 45.65$ trillion. The United States and Europe are the most relevant industries, accounting for $46 \%$ and $34 \%$ of the worldwide distribution of mutual fund assets, respectively (The European Fund and Asset Management Association EFAMA, 2018).

Since the seminal paper of Sharpe (1966), an extensive body of literature has sought to clarify the performance value of active management. Relevant performance measures have been developed mainly based on portfolio return records (e.g., Jensen, 1968; Fama and French, 1993; Grinblatt and Titman, 1993; Elton et al., 1996) and portfolio holdings (e.g., Grinblatt and Titman, 1989; Daniel et al., 1997). In addition, many papers have focused on the persistence of the results of active management (e.g., Carhart, 1997; Wermers, 2000; Bollen and Busse, 2004; French, 2008; Fama and French, 2010).

Traditionally, the assessment of active management has relied on tracking error (TE), which is the divergence of portfolio returns relative to a benchmark. More formally, Rudolf et al. (1999) define TE as the time-series standard deviation of the difference between portfolio and benchmark returns. The objective of active management is to obtain higher returns than the benchmark as well as a low TE.

Cremers and Petajisto (2009) proposed Active Share (AS) to measure the percentage of portfolio holdings of a mutual fund that differ from its benchmark holdings ${ }^{2}$,

$$
\text { Active Share }(A S)=\frac{1}{2} \sum_{i=1}^{N}\left|w_{\text {fund }, i}-w_{\text {benchmark }, i}\right|
$$

where $w_{f u n d, i}$ and $w_{\text {benchmark }, i}$ are the portfolio weights of stock $i$ in the mutual fund and the benchmark, respectively, and $N$ is the total number of stocks that is included in either the fund or the benchmark.

\footnotetext{
${ }^{1}$ According to Morningstar statistics, worldwide, non-active funds represented $27 \%$ of total funds managed in 2017, up from $16 \%$ in 2010.

${ }^{2}$ Recently, Cremers (2017) introduced a new formula for AS. This formula expresses AS as equal to $100 \%$ minus the sum of the overlapping weights between the portfolio and its benchmark, thus emphasizing that AS is only lowered by overlapping positions that are in both the fund and the benchmark. Although this new approach tends to facilitate the use of AS in computational terms, AS continues to rely on both the choice of benchmark and the portfolio management style.
} 
According to Cremers and Petajisto (2009) and Petajisto (2013), AS and TE emphasize different aspects of active management. AS is a reasonable proxy to identify security selection, while TE is better suited to measuring the volatility of portfolio returns relative to the benchmark. These two dimensions together cover the level and the sources of active management. AS matters for investors in three ways. First, AS may be helpful in selecting actively managed funds, that is, funds overseen by managers who are willing to beat the benchmark. Second, AS enables one to obtain a proxy of managers' potential stock-picking abilities when they overweight (underweight) stocks that beat (are beaten by) the benchmark. Third, investors with access to AS would be more likely to evaluate the management fees charged by mutual funds with respect to the level of active management.

Since the seminal paper of Cremers and Petajisto (2009), numerous papers have successfully applied AS to US mutual funds. Schlanger et al. (2012) show that AS can play a useful role in manager selection. Cremers and Pareek (2016) explain and predict the ability of portfolio managers to use both high active share and patient investment strategies to outperform their benchmarks. Other papers support the aforementioned advantages of applying AS in US mutual funds. For example, Jiang et al. (2014) find that overweighted positions in funds relative to their benchmarks have outperformed their underweighted positions, showing the shrinking fraction of assets managed by activefund managers.

Muller and Weber (2012), Lee and Morri (2015), Cremers et al. (2016) and Frijns and Indriawan (2018) are recent papers confirming that previous results for US mutual funds hold in other markets, such as New Zealand and Europe.

However, not all academics support the aforementioned results. For instance, Muller and Ward (2011), in contrast to previous studies, find no relationship between the level of AS and mutual fund returns in the South African market. More recently, Ang et al. (2017) also find that there is no significant evidence that AS identifies skilled active management and predicts future performance. Moreover, AS seems to be far from stable, as Huang et al. (2011) show that mutual funds significantly change their risk level over time.

The strongest claims against the AS are found in Frazzini et al. (2016), who show that mutual funds with the highest AS measures are related to small and mid-cap stock benchmarks and the poor performance records of these benchmarks over the 1990-2009 period. AS is very sensitive to the benchmark characteristics, and the AS results will therefore be driven by this measure's strong dependence on the benchmark. The choice of 
inappropriate benchmarks that do not properly reflect the portfolio's investment style will result in inaccurate AS. However, Petajisto (2016) recently refuted these claims, noting that the analysis has significant faults and ignores relevant discussion, according to the previous findings included in Cremers and Petajisto (2009) and Petajisto (2013).

In addition to addressing the aforementioned problem, this paper provides evidence of the potentially misleading results that the application of AS provides when concentrated benchmarks are considered. Specifically, the accumulated weight of equity benchmark constituents in domestic Eurozone markets is highly concentrated in fewer constituents than in US benchmarks. Focusing on US mutual funds, we can observe that in the S\&P 500 benchmark, the weight of the top 10 constituents is $20.7 \%$ and the largest weight of a constituent is $3.7 \%$ (S\&P Dow Jones Index, 2018). In the Eurozone, we find domestic benchmarks with heavy concentration levels. For example, the accumulated weight of the top 10 constituents in the IBEX 35 Spanish benchmark is $70.82 \%$, with the largest weight of a constituent being 14.34\% (Bolsa de Madrid, 2019). However, we also find domestic Eurozone benchmarks with lower levels of concentration. For example, the accumulated weight of the top 10 constituents in the CAC 40 French benchmark is $54.81 \%$, and the largest weight of a constituent is $11.14 \%$ (CAC 40 Index, December 2018).

Accordingly, 1) the AS obtained in US mutual funds cannot be compared with the AS obtained in mutual funds in the Eurozone, and 2) the AS obtained in the different domestic Eurozone markets are not comparable to each other due to the assorted concentration levels of the domestic Eurozone benchmarks. The main contribution of our paper is to obtain comparable results given that our approach controls the effect of the different concentration levels of each benchmark in the context of legal restrictions on the portfolio concentration.

In addition to the limitations previously identified, it is necessary to test how the current European directive on the risk of portfolio diversification will influence AS accuracy. The Directive 2009/65/EC sets the rules relating to mutual funds as one of the major financial instruments included in the Undertaking for Collective Investments in Transferable Securities (UCITS) category ${ }^{3}$. It is the fourth version of UCITS legislation, recasting the seminal UCITS Directive 85/611/EEC.

\footnotetext{
${ }^{3}$ UCITS was devised to facilitate cross-border investments within the EU. The aim of the UCITS directive was to remove barriers to the cross-border marketing of units of collective investment funds within the EU by allowing funds to invest in a broader range of financial instruments and streamlining the regulations of different countries.
} 
Because mutual funds are designed to be suitable for retail investors, their rules are based on certain levels of portfolio diversification with the aim of reducing their vulnerability to the performance of a small number of assets. The current Directive 2009/65/EC specifies in article 52 (paragraph 1) that "UCITS shall invest no more than $5 \%$ of its assets in transferable securities or money market instruments issued by the same body; or $20 \%$ of its assets in deposits made with the same body. Member States may raise the $5 \%$ limit laid down in the first subparagraph of paragraph 1 to a maximum of $10 \%$. If they do so, however, the total value of the transferable securities and the money market instruments held by the UCITS in the issuing bodies in each of which it invests more than $5 \%$ of its assets shall not exceed $40 \%$ of the value of its assets. That limitation shall not apply to deposits or OTC derivative transactions made with financial institutions subject to prudential supervision"

On the one hand, the domestic Eurozone benchmarks show a variety of characteristics in terms of the concentrations of their constituents. On the other hand, there are regulatory issues that prevent portfolio concentration. This framework could involve conflicting patterns in the search for active management based on the AS. That is, the high concentration level detected in the domestic Eurozone benchmarks conflicts with the $10 \%$ concentration limit generally included in the regulation. Therefore, for concentrated benchmarks that include constituents weighted close to or above $10 \%$, mutual funds are not allowed to overweight those constituents in their portfolios. In fact, the only way they can achieve extra AS is by underweighting such constituents. In practice, the aforementioned framework means that there are significant limits to increasing AS, even for actively managed mutual funds.

Our paper is the first to evaluate the consequences of both the assorted characteristics of domestic Eurozone benchmarks and the European regulation preventing portfolio concentration in the appropriate estimation of AS. Furthermore, our study identifies truly active management in domestic equity funds (mutual funds that invest principally in domestic stocks) in the Eurozone markets, solving the aforementioned bias.

Our findings suggest that the high concentration level and the heterogeneity present in the domestic equity funds in the Eurozone prevent the direct comparability of the AS. Therefore, it would be necessary to consider the level of AS over the spurious level and the characteristics of every market, each of which produces significant and different styles of active management.

\footnotetext{
${ }^{4}$ In terms of investment constraints, Article 52 in the Directive 2009/65/EC is similar to Article 22 in the seminal Directive 85/611/EEC. Thus, this specific part of the EU regulation has not changed since 1985.
} 
This paper has important implications for policymakers and practitioners of the domestic equity fund industries in the Eurozone. In the strongly regulated European markets (Benink and Schmidt, 2014), where policy literature are consistent in the importance of detection of market abuse (Cumming et al., 2018), our unbiased approach allows these market players to identify the accurate levels of active management of each industry after considering both the regulation of portfolio diversification and the concentrated domestic equity benchmarks. Market supervisors will have a better picture of the active management map to develop appropriate regulations of the mutual fund industry. In addition, our approach should help practitioners and investors to effectively find out the level of active management of domestic equity funds and therefore provide information for fund management companies to replace for no actual performing managers (Clare et al., 2014). Besides, our results should help to reduce opacity in the management fees charged by the funds are justified by accurate measures of active management (Casavecchia and Hulley, 2018)

The remainder of the paper is as follows. We describe the data from Eurozone Benchmarks in Section 2. Section 3 describes the method of obtaining spurious Active Shares. Section 4 determines the significant Active Share above the spurious level. Section 5 presents the empirical application to domestic equity funds in the Eurozone markets. Finally, Section 6 concludes the paper. 


\section{Data}

We select those mutual fund industries that have been present in the constitution of the Eurozone $^{5}$. These markets share at least eighty percent of the total net assets (TNA) of European mutual funds from 1999 to 2016 (Investment company Institute, 2017) and at least eighty-three percent of domestic equity funds in the European mutual fund industry (EFAMA, 2017).

From Morningstar, we select the most frequent primary prospectus benchmark reported by the domestic equity funds registered in each Eurozone member ${ }^{6}$. Datastream provides comprehensive data of these relevant benchmarks. We obtain the monthly characteristics of each domestic benchmark, such as their constituent identifications (ISIN code) and their constituent weights. Our benchmark sample covers January 2002 to December 2016 and includes 45,735 constituent weights.

Table 1 reports descriptive statistics of our final benchmark sample ${ }^{7}$. From the information provided by the maximum weight of a benchmark constituent together with the number of constituents over a $10 \%$ weight, we identify the potential conflicts between the benchmarks and the limits of the portfolio concentration established in the Directive 2009/65/EC. In addition, we use the Herfindahl-Hirschman index (HHI) to compare the concentration levels of our domestic benchmark sample ${ }^{8}$. All these figures highlight the potential problems in AS accuracy with respect to portfolio concentration limits, especially in the most concentrated benchmarks of our sample, such as ATX 20 (Austria), BEL 20 (Belgium), ATHEX 20 (Greece), PSI 20 (Portugal) and IBEX 35 (Spain). In contrast, CAC 40 (France) and DAX 30 (Germany) are the least controversial domestic Eurozone benchmarks in terms of $\mathrm{HHI}^{9}$.

\footnotetext{
${ }^{5}$ This area was created in 1999 by eleven founding states: Austria, Belgium, Finland, France, Germany, Ireland, Italy, Luxembourg, the Netherlands, Spain and Portugal. Greece joined the Eurozone in 2001. Coins and banknotes were first used on $1^{\text {st }}$ January 2002 in all twelve Euro member states. Luxembourg and Ireland are excluded from our sample for two different reasons. First, there is not a specific domestic benchmark in Luxembourg and second, Morningstar does not provide a domestic equity category for Irish mutual funds.

${ }^{6}$ We assume a potential benchmark 'gaming' in the selection of our sample (Sensoy, 2009). But even though the primary prospectus benchmark may not match the fund's style, it should be included as funds will likely present high AS figures. Otherwise, this exclusion might influence our further empirical results.

${ }^{7}$ Datastream does not provide information for benchmark constituents for ATHEX 20 (Greece), FTSE MIB 40 (Italy), and PSI 20 (Portugal) for 2002-2005, 2002-2003 and 2002-2006, respectively.

${ }^{8} \mathrm{HHI}$ is an index that measures the market concentration of an industry and is calculated by squaring the market share of each firm competing in the market and then summing the resulting numbers. The index ranges from 0 to 10,000. The relative comparison of the HHI figures of our benchmark sample permits the identification of the level of concentration of each domestic benchmark in relation to the others.

${ }^{9}$ Our domestic sample includes much more concentrated benchmarks than overall Eurozone and European benchmarks such as Eurostoxx 50 (HHI=282.44) and Eurofirst 100 (HHI=371.48), respectively. We get similar conclusions for well-known benchmarks of both the US market (S\&P 500, HHI=133.32) and the UK market (FTSE 100, HHI=323.07). Further details are available upon request.
} 


\section{Definition of spurious Active Share}

In this section, we assess a spurious AS (sAS) resulting from the divergence between the limits established by the regulation on risk diversification in Europe (by the Directive 2009/65/EC) and the high levels of concentration of the domestic Eurozone benchmarks, which, in many cases, exceed the maximum weight per constituent allowed by the regulation. We develop an algorithm that identifies sAS as the minimum AS driven by both the requirements of the European regulation and the benchmark concentration. That is, sAS is the minimum AS that is not a consequence of active decisions made by the equity fund manager (see details of the whole process of this algorithm in Appendix 1).

In our algorithm, we work with the weights $w_{i}$ of the $i=1 \ldots, n$ constituents that are part of each domestic Eurozone benchmark on a monthly basis. The weight of each constituent $i$ is positive, and the sum of these weights for each benchmark is $100 \%$.

$$
\begin{array}{lr}
w_{i}>0 & \forall i \\
\sum_{i=1}^{n} w_{i}=100 \%
\end{array}
$$

First, we sort the weights of the $n$ benchmark constituents from the highest to the lowest into three excluding groups $(j, k, l)$ based on the limits of portfolio concentration in article 52 of the Directive 2009/65/EC.

$$
\begin{array}{ll}
\text { If } w_{i}>10 \% \text { then rename } w_{i} \text { as } w_{i}^{j} & \forall i \\
\text { If } 5 \% \leq w_{i} \leq 10 \% \text { then rename } w_{i} \text { as } w_{i}^{k} & \forall i \\
\text { If } w_{i}<5 \% \text { then rename } w_{i} \text { as } w_{i}^{l} & \forall i
\end{array}
$$

These groups let us identify the weights over the concentration limits that must be truncated to achieve the diversification rules included in the Directive 2009/65/EC. This process is first applied in group $j$ of benchmark constituents by reducing their original weights to $10 \%$.

$$
\text { If } w_{i}^{j}>10 \% \text { then } w_{i}^{j^{\prime}}=10 \% \quad \forall i
$$

With $J$ being the sum of the truncated weights of the constituents in group $j$.

$$
J=\sum_{i=1}^{n} w_{i}^{j^{\prime}}
$$

After that, we follow the process in group $k$ of benchmark constituents ${ }^{10}$. We must consider both the previously recalculated weights of the constituents of group $j$ (8) and the original weights of the constituents of group $k$ and obtain the sum of both groups, constituent by constituent (from the highest to the lowest weight). If the sum is greater

\footnotetext{
${ }^{10}$ In unusual cases when the number of constituents with a value over $10 \%$ is five or more, the fifth and subsequent constituents in group $j$ are included in group $k$. Then, the weights of all constituents in group $k$ are truncated to 5\% following the Directive 2009/65/EC.
} 
than $40 \%$, then reduce the weights of the constituents in group $k$ from their original weights to $5 \%$.

$$
\begin{aligned}
& \text { For } p=1 \text { to } n \\
& \text { If }\left(J+\sum_{i=1}^{p} w_{i}^{k}\right) \leq 40 \% \text { then } w_{i}^{k^{\prime \prime}}=w_{i}^{k} \\
& \text { If }\left(J+\sum_{i=1}^{p} w_{i}^{k}\right)>40 \% \text { then } w_{i}^{k^{\prime}}=5 \% \\
& \text { Next } p
\end{aligned}
$$

\section{Next $p$}

We define $w$ as the sum of the previously obtained weights of the benchmark constituents fulfilling the limits of portfolio concentration, i.e., the recalculated weights of group $j$, and $k$ and the original weights of group $l$. The sum of these weights will be $100 \%$ only if the previous steps (7) and (9) have modified none of the weights of the constituents.

$$
w=\left(J+\sum_{i=1}^{n} w_{i}^{k^{\prime}}+\sum_{i=1}^{n} w_{i}^{k^{\prime \prime}}+\sum_{i=1}^{n} w_{i}^{l}\right)
$$

Finally, we obtain sAS as the difference between $100 \%$ minus $w$, and it shows the accumulated excess weights over the concentration limits, which are not a consequence of active management. Thus, sAS is the minimum AS that should be found in a portfolio following the diversification rules imposed by the Directive 2009/65/EC.

$$
s A S=100 \%-w
$$

We apply the algorithm to monthly information on the constituents of all domestic Eurozone benchmarks included in our sample. Table 2 shows a summary of the annual values of sAS for each benchmark during 2002-2016. We find assorted evidence due to the EU diversification requirements and the different levels of concentration in the domestic Eurozone benchmarks. PSI 20 (Portugal), ATX 20 (Austria) and IBEX 35 (Spain) obtain the highest average sAS values, with $22.4 \%, 18.60 \%$ and $17.99 \%$, respectively. By contrast, there are benchmarks that present much lower levels of sAS, such as CAC 40 (France), DAX 30 (Germany) and OMXH 25 (Finland), with 3.31\%, $5.50 \%$ and $5.80 \%$, respectively. These results provide evidence that the Directive 2009/65/EC negatively influences the accuracy of the AS shown for managers who work with very concentrated domestic Eurozone benchmarks. In contrast, the sAS evidence for the least concentrated domestic Eurozone benchmarks shows that AS reported by managers who work in France, Germany and Finland are much more accurate. Therefore, our findings confirm that AS values obtained in different domestic Eurozone markets are not comparable. The next section will further develop a new tool to identify accurate AS estimations. 
Table 1

Domestic equity benchmarks. Summary statistics. This table presents descriptive statistics of the ten domestic equity benchmarks included in our sample from 2002 to 2016 for every year and country. This table shows (1) the maximum weight of a constituent in each benchmark, (2) the number of constituents over a $10 \%$ weight in the benchmark and (3) the median value of the Herfindahl-Hirschman index (HHI), which is a proxy for the concentration level of each benchmark.

\begin{tabular}{|c|c|c|c|c|c|c|c|c|c|c|c|c|c|c|c|}
\hline \multirow[b]{2}{*}{ Year } & \multicolumn{3}{|c|}{ (AEX 25) NETHERLANDS } & \multicolumn{3}{|c|}{ (ATHEX 20) GREECE } & \multicolumn{3}{|c|}{ (ATX 20) AUSTRIA } & \multicolumn{3}{|c|}{ (BEL 20) BELGIUM } & \multicolumn{3}{|c|}{ (CAC 40) FRANCE } \\
\hline & $(1)$ & (2) & (3) & $(1)$ & $(2)$ & (3) & (1) & $(2)$ & (3) & $(1)$ & (2) & (3) & (1) & (2) & (3) \\
\hline 2002 & 14.96 & 4 & 758.72 & na & na & na & 23.16 & 3 & 998.55 & 23.22 & 3 & 1138.10 & 16.46 & 1 & 506.50 \\
\hline 2003 & 14.62 & 3 & 732.33 & na & na & na & 21.29 & 4 & 1070.18 & 24.34 & 3 & 1172.94 & 15.78 & 1 & 497.49 \\
\hline 2004 & 11.79 & 4 & 762.24 & na & na & na & 21.14 & 3 & 1123.12 & 24.72 & 3 & 1102.95 & 18.23 & 2 & 546.02 \\
\hline 2005 & 16.60 & 3 & 888.66 & na & na & na & 21.93 & 3 & 1111.75 & 22.72 & 5 & 958.86 & 15.68 & 2 & 556.08 \\
\hline 2006 & 16.51 & 3 & 888.07 & 22.40 & 4 & 1063.40 & 22.44 & 4 & 1061.21 & 18.41 & 4 & 1032.01 & 13.46 & 1 & 498.35 \\
\hline 2007 & 18.90 & 3 & 850.58 & 23.00 & 3 & 1010.90 & 19.69 & 4 & 1037.10 & 18.71 & 5 & 973.77 & 12.95 & 1 & 451.46 \\
\hline 2008 & 23.66 & 4 & 977.16 & 23.19 & 3 & 951.44 & 20.19 & 4 & 1058.73 & 24.21 & 5 & 956.23 & 17.03 & 1 & 516.15 \\
\hline 2009 & 22.63 & 3 & 789.66 & 27.23 & 3 & 1025.26 & 20.14 & 3 & 920.94 & 19.50 & 4 & 809.73 & 17.96 & 1 & 510.64 \\
\hline 2010 & 17.12 & 3 & 812.40 & 23.46 & 2 & 947.00 & 21.58 & 4 & 945.52 & 19.27 & 3 & 731.46 & 12.82 & 1 & 469.62 \\
\hline 2011 & 19.42 & 3 & 859.65 & 20.19 & 4 & 877.85 & 21.83 & 3 & 901.40 & 17.90 & 2 & 732.05 & 14.39 & 2 & 475.32 \\
\hline 2012 & 18.22 & 3 & 829.96 & 23.25 & 4 & 895.87 & 19.93 & 4 & 833.69 & 14.62 & 3 & 754.52 & 14.00 & 2 & 521.46 \\
\hline 2013 & 16.75 & 3 & 772.72 & 24.14 & 3 & 913.24 & 21.34 & 3 & 995.96 & 14.40 & 3 & 771.00 & 13.44 & 2 & 499.09 \\
\hline 2014 & 17.23 & 3 & 835.61 & 18.51 & 4 & 813.38 & 19.92 & 4 & 893.24 & 15.69 & 4 & 788.18 & 12.84 & 2 & 478.64 \\
\hline 2015 & 17.40 & 3 & 838.33 & 30.47 & 3 & 879.03 & 22.10 & 4 & 924.49 & 15.69 & 4 & 782.64 & 11.23 & 2 & 443.79 \\
\hline 2016 & 17.18 & 3 & 818.62 & 22.07 & 3 & 920.17 & 21.86 & 3 & 930.21 & 13.94 & 4 & 788.93 & 17.99 & 1 & 414.13 \\
\hline Average & 17.53 & 3 & 827.65 & 23.45 & 3 & 936.14 & 21.24 & 4 & 987.07 & 19.16 & 4 & 899.56 & 14.95 & 1 & 492.32 \\
\hline
\end{tabular}

\begin{tabular}{|c|c|c|c|c|c|c|c|c|c|c|c|c|c|c|c|}
\hline \multirow[b]{2}{*}{ Year } & \multicolumn{3}{|c|}{ (DAX 30) GERMANY } & \multicolumn{3}{|c|}{ (FTSE MIB 40) ITALY } & \multicolumn{3}{|c|}{ (IBEX 35) SPAIN } & \multicolumn{3}{|c|}{ (OMXH 25) FINLAND } & \multicolumn{3}{|c|}{ (PSI 20) PORTUGAL } \\
\hline & (1) & (2) & (3) & (1) & (2) & (3) & (1) & (2) & (3) & (1) & (2) & (3) & (1) & (2) & (3) \\
\hline 2002 & 12.42 & 3 & 643.79 & na & na & na & 23.38 & 3 & 992.27 & 11.77 & 2 & 625.64 & na & na & na \\
\hline 2003 & 13.12 & 2 & 642.16 & na & na & na & 21.39 & 3 & 965.95 & 12.56 & 4 & 655.12 & na & na & na \\
\hline 2004 & 12.28 & 2 & 622.56 & 17.58 & 2 & 743.27 & 21.94 & 3 & 979.97 & 41.55 & 3 & 649.4 & na & na & na \\
\hline 2005 & 10.82 & 2 & 590.77 & 20.78 & 2 & 827.95 & 19.54 & 3 & 893.17 & 11.49 & 4 & 635.24 & na & na & na \\
\hline 2006 & 11.26 & 2 & 577.32 & 17.77 & 3 & 838.51 & 17.55 & 3 & 869.98 & 52.41 & 2 & 618.89 & na & na & na \\
\hline 2007 & 10.86 & 2 & 580.97 & 17.15 & 3 & 833.89 & 20.22 & 4 & 887.65 & 12.26 & 2 & 615.66 & 20.46 & 4 & 994.70 \\
\hline 2008 & 13.91 & 2 & 581.54 & 18.27 & 5 & 854.40 & 23.89 & 4 & 1058.19 & 31.79 & 3 & 627.26 & 18.59 & 4 & 1001.91 \\
\hline 2009 & 10.85 & 2 & 589.72 & 16.77 & 4 & 824.19 & 25.83 & 3 & 1237.91 & 11.00 & 3 & 603.39 & 20.41 & 5 & 920.94 \\
\hline 2010 & 10.53 & 1 & 562.14 & 16.40 & 4 & 824.02 & 23.74 & 3 & 1224.26 & 10.47 & 2 & 607.79 & 19.88 & 4 & 1025.5 \\
\hline 2011 & 10.44 & 1 & 553.67 & 17.11 & 4 & 765.16 & 21.50 & 3 & 1032.22 & 12.99 & 4 & 625.23 & 20.05 & 4 & 1113.92 \\
\hline 2012 & 10.15 & 1 & 563.90 & 16.56 & 3 & 673.14 & 19.11 & 4 & 974.83 & 13.03 & 3 & 641.00 & 19.41 & 4 & 1177.02 \\
\hline 2013 & 10.25 & 1 & 573.29 & 15.35 & 2 & 650.56 & 18.85 & 4 & 900.63 & 15.84 & 3 & 625.06 & 17.39 & 5 & 1076.45 \\
\hline 2014 & 10.62 & 1 & 571.22 & 15.97 & 4 & 685.55 & 18.76 & 3 & 818.48 & 11.30 & 3 & 645.33 & 19.72 & 5 & 1023.96 \\
\hline 2015 & 10.27 & 1 & 560.72 & 13.76 & 2 & 639.99 & 17.86 & 4 & 788.22 & 10.98 & 3 & 626.93 & 18.22 & 5 & 944.35 \\
\hline 2016 & 10.25 & 1 & 554.47 & 15.52 & 3 & 623.15 & 14.94 & 3 & 697.10 & 10.96 & 2 & 614.17 & 16.55 & 5 & 965.22 \\
\hline Average & 11.20 & 2 & 584.55 & 16.85 & 3 & 752.60 & 20.57 & 3 & 954.72 & 18.03 & 3 & 627.74 & 19.07 & 5 & 1024.40 \\
\hline
\end{tabular}


Table 2

Spurious Active Share (sAS) from 2002 to 2016. This table presents the annual statistics of sAS (in percent terms) of the ten domestic equity benchmarks included in our sample from 2002 to 2016 for every year and country. These average results are computed from the monthly sAS obtained for our sample of domestic Eurozone benchmarks.

\begin{tabular}{|c|c|c|c|c|c|c|c|c|c|c|c|c|}
\hline Year & $\begin{array}{c}\text { (AEX 25) } \\
\text { NETHERLANDS } \\
\end{array}$ & $\begin{array}{l}\text { (ATHEX 20) } \\
\text { GREECE } \\
\end{array}$ & $\begin{array}{r}\text { (ATX 20) } \\
\text { AUSTRIA } \\
\end{array}$ & $\begin{array}{c}\text { (BEL 20) } \\
\text { BELGIUM }\end{array}$ & $\begin{array}{l}\text { (CAC 40) } \\
\text { FRANCE }\end{array}$ & $\begin{array}{c}\text { (DAX 30) } \\
\text { GERMANY }\end{array}$ & $\begin{array}{l}\text { (FTSE MIB 40) } \\
\text { ITALY } \\
\end{array}$ & $\begin{array}{l}\text { (IBEX 35) } \\
\text { SPAIN }\end{array}$ & $\begin{array}{l}\text { (OMXH 25) } \\
\text { FINLAND }\end{array}$ & $\begin{array}{c}\text { (PSI 20) } \\
\text { PORTUGAL }\end{array}$ & Average & St. Dev. \\
\hline 2002 & 12.69 & na & 18.70 & 24.76 & 4.51 & 7.22 & na & 19.24 & 5.51 & na & 13.23 & 7.28 \\
\hline 2003 & 12.11 & na & 19.61 & 24.88 & 3.42 & 9.44 & na & 18.56 & 8.44 & na & 14.61 & 6.95 \\
\hline 2004 & 12.93 & na & 23.58 & 19.59 & 5.68 & 7.84 & 10.16 & 18.64 & 7.20 & na & 13.20 & 6.21 \\
\hline 2005 & 17.81 & na & 23.47 & 19.19 & 5.10 & 5.68 & 13.39 & 16.21 & 4.87 & na & 13.21 & 6.74 \\
\hline 2006 & 17.22 & 20.24 & 19.78 & 20.88 & 2.96 & 3.70 & 15.30 & 16.39 & 4.51 & na & 13.44 & 7.09 \\
\hline 2007 & 16.51 & 19.96 & 22.53 & 19.32 & 2.38 & 3.42 & 15.68 & 16.53 & 4.51 & 23.38 & 14.42 & 7.59 \\
\hline 2008 & 19.48 & 18.62 & 20.96 & 17.69 & 5.15 & 5.67 & 15.87 & 20.71 & 5.74 & 21.08 & 15.10 & 6.45 \\
\hline 2009 & 12.61 & 18.75 & 18.24 & 14.70 & 4.07 & 5.65 & 14.72 & 25.03 & 4.61 & 19.36 & 13.77 & 6.71 \\
\hline 2010 & 13.45 & 16.99 & 17.22 & 11.85 & 2.22 & 6.28 & 13.98 & 25.01 & 4.45 & 22.09 & 13.35 & 7.04 \\
\hline 2011 & 14.25 & 14.56 & 16.34 & 11.86 & 3.08 & 5.04 & 10.88 & 21.54 & 5.43 & 24.87 & 12.79 & 6.73 \\
\hline 2012 & 13.54 & 14.73 & 15.75 & 12.55 & 4.61 & 3.42 & 8.46 & 20.71 & 6.24 & 25.21 & 12.52 & 6.68 \\
\hline 2013 & 12.30 & 14.50 & 19.54 & 13.00 & 3.14 & 4.10 & 7.97 & 16.89 & 5.91 & 24.99 & 12.23 & 6.71 \\
\hline 2014 & 14.09 & 14.71 & 15.11 & 13.22 & 2.33 & 4.20 & 8.33 & 13.22 & 5.78 & 21.26 & 11.23 & 5.57 \\
\hline 2015 & 14.11 & 17.31 & 14.05 & 13.32 & 0.70 & 5.45 & 6.88 & 11.52 & 4.29 & 21.83 & 10.95 & 6.17 \\
\hline 2016 & 12.40 & 16.70 & 14.13 & 12.47 & 0.32 & 5.40 & 6.10 & 9.59 & 3.38 & 19.98 & 10.05 & 5.89 \\
\hline Average & 14.37 & 16.76 & 18.60 & 16.48 & 3.31 & 5.50 & 11.44 & 17.99 & 5.80 & 22.40 & 13.26 & 6.65 \\
\hline St. Dev. & 2.29 & 2.19 & 3.17 & 4.59 & 1.58 & 1.70 & 3.60 & 4.41 & 1.27 & 2.11 & 1.39 & 0.53 \\
\hline
\end{tabular}




\section{Determination of the significant AS above the spurious level}

To obtain proper valuations of the active management of domestic equity funds in the Eurozone, we first define domestic Eurozone sAS-based benchmarks, which fulfil the portfolio concentration limits of the Directive 2009/65/EC. Then, we propose specific thresholds at $90 \%, 95 \%$ and $99 \%$ for each year and market to determine the statistical significance of each AS obtained.

The first step of this process is focused on the distribution of the sAS obtained in the previous section to the benchmark constituents belonging to subgroup $k^{\prime \prime}$ and group $l$, both of which can incorporate additional weights because $w_{i}^{k^{\prime \prime}}$ and $w_{i}^{l}$ are below the limits of portfolio concentration, such as $10 \%$ or $5 \%$, respectively. This distribution is proportional to the original weights of these constituents in the benchmark and should never lead the new weights to exceed such portfolio limits.

From equation (11): $s A S=100 \%-w$, we define $w^{\prime}$ as the sum of the weights of the constituents, which fulfils the distribution of the EU diversification rules included in sAS.

$$
w^{\prime}=\sum_{i=1}^{n} w_{i}^{k^{\prime \prime}}+\sum_{i=1}^{n} w_{i}^{l}
$$

We identify the proportion of the original weight of each constituent in the benchmark, which may incorporate whatever sAS with respect to the total weight of these constituents.

$$
r w_{i}=w_{i} / w^{\prime} \quad \forall i
$$

In the next step, we first distribute sAS proportionally to $w_{i}^{k^{\prime \prime}}$, constituent by constituent (from the highest to the lowest weight). The distribution will stop when the sum of the weights of the constituents included in $J$ and group $k$ is equal to $40 \%{ }^{11}$.

$$
\begin{aligned}
& \text { For } p=1 \text { to } n \\
& \text { If }\left(J+\sum_{i=1}^{p} w_{i}^{k^{\prime}}+\sum_{i=1}^{p} w_{i}^{k^{\prime \prime}}\right)<40 \% \text { then } w_{i}^{k^{\prime \prime \prime}}=r w_{i} \times \mathrm{s} A S+w_{i}^{k^{\prime \prime}} \\
& \text { Being } w_{i}^{k^{\prime \prime \prime}} \leq 10 \% \quad \forall i \epsilon w_{i}^{k^{\prime \prime \prime}} \\
& \text { If }\left(J+\sum_{i=1}^{p} w_{i}^{k^{\prime}}+\sum_{i=1}^{p} w_{i}^{k^{\prime \prime}}\right)=40 \% \text { then stop loop } \\
& \text { Next } p
\end{aligned}
$$

\footnotetext{
${ }^{11}$ In unusual cases when the proportional increase leads the new weight of a constituent included in group $k$ to exceed the $10 \%$ limit, the algorithm should be initialised in step (7) with the recalculated weights.
} 
Then, we continue with the proportional distribution of sAS to group $l$, constituent by constituent (from the highest to the lowest weight) as long as sAS is higher than zero because step (14) has not fully finished distributing $\mathrm{sAS}^{12}$.

$$
\begin{aligned}
& \text { For } p=1 \text { to } n \\
& \text { I } f\left(w+\sum_{i=1}^{p} w_{i}^{k^{\prime \prime \prime}}\right)<100 \% \text { then } w_{i}^{l^{\prime}}=r w_{i} \times s A S+w_{i}^{l} \\
& \begin{array}{ll}
\text { Being } w_{i}^{l^{\prime}} \leq 5 \% & \forall i \in w_{i}^{l} \\
\text { Next } p &
\end{array}
\end{aligned}
$$

We define $w^{\prime \prime}$ as the sum of the weights of the benchmark constituents fulfilling the limits of portfolio concentration. If the sum of the constituent weights is $100 \%$, the proportional distribution is complete. If not, it is necessary to repeat step (15) until $w^{\prime \prime}$ is equal to $100 \%{ }^{13}$.

$$
w^{\prime \prime}=\left(w+\sum_{i=1}^{n} w_{i}^{k^{\prime \prime \prime}}+\sum_{i=1}^{n} w_{i}^{l^{\prime}}\right) \quad \forall i
$$

Now, the constituent weights of each domestic Eurozone benchmark previously obtained are fulfilling the limits of portfolio concentration as stipulated by Directive 2009/65/EC. Next, we perform an analysis to calculate AS-thresholds that represent the minimum values of AS to confirm that the analysed portfolio is significantly active at 90\%, 95\% and 99\% confidence levels. Due to the lack of information about fitted parametric distributions of the benchmark constituent weights, we develop confidence thresholds based on the historical distributions of these constituent weights in our study period. First, we achieve 200,000 monthly simulations with $w^{\prime \prime}$ using a 60-month fixed rolling window ${ }^{14}$. Second, we normalize up to $100 \%$ of the weight obtained in each simulation to assure that the total sum of the weights for each simulation is $100 \%$. Then, we apply steps (2) to (16) from the algorithm presented in the previous sections to comply with Directive 2009/65/EC. Then, we obtain the differences between the real and the simulated weights of each benchmark constituent. That is, we calculate the original AS, equation (1), but we replace $w_{f u n d, i}$ with the simulated weight of each benchmark constituent fulfilling the EU concentration limits.

Third, we develop AS-thresholds with the monthly simulations of AS for each month and domestic Eurozone benchmark; to do this, we use statistical inference

\footnotetext{
${ }^{12}$ In unusual cases when the proportional increase leads the new weight of a constituent included in group $l$ to exceed the 5\% limit, the algorithm should be initialised in step (9) with the recalculated weights.

${ }^{13}$ If the sum of both constituent weights is not $100 \%$ and $\left(J+\sum_{i=1}^{p} w_{i}^{k^{\prime}}+\sum_{i=1}^{p} w_{i}^{k^{\prime \prime}}\right)<40$, it is necessary to repeat steps (14) and (15) until $w^{\prime \prime}=100 \%$.

${ }^{14}$ For ATHEX 20 (Greece), FTSE MIB 40 (Italy), and PSI 20 (Portugal) the simulations begin when the sixty first weights are available. Further details about the simulation are not shown for the sake of brevity.
} 
according to the values for the 90th, 95th and 99th percentiles of all AS simulations for each month and benchmark. These three thresholds will be the minimum values of AS required to confirm that the analysed portfolio is significantly active at $90 \%, 95 \%$ and $99 \%$ confidence levels.

Table 3 presents the monthly average of AS-thresholds for each year in each domestic Eurozone benchmark during the 2007-2016 period ${ }^{15}$. These results are driven by both the level of concentration of the different domestic Eurozone benchmarks and the EU limits on portfolio concentration, as we discussed in the previous section.

The striking differences reported by Table 3 confirm our hypothesis that the AS results in the domestic equity funds in the Eurozone being not directly compatible due to portfolio concentration limits defined in Directive 2009/65/EC. For instance, a domestic equity fund in the Portuguese market with an AS of 20\% in 2013 shows no significant active management at 90\%, 95\% and 99\% confidence levels. Instead, a domestic equity fund in the French market in the same period with an AS of $20 \%$ is significantly active at $90 \%$ and $95 \%$ but not at the $99 \%$ confidence level.

Table 3 allows testing for the statistical significance of the original AS obtained by domestic equity funds of the Eurozone for the period 2007-2016. Table 3 also shows consistent and stable thresholds across benchmarks and years, which leads us to use them in the empirical analysis included in the following section.

\footnotetext{
${ }^{15}$ Detailed monthly information is available on request.
} 
Table 3

AS-thresholds of domestic equity benchmarks of the Eurozone. This table presents the monthly average (in percent terms) of AS-thresholds at $90 \%, 95 \%$ and $99 \%$ confidence levels during the period 2007-2016.

\begin{tabular}{|c|c|c|c|c|c|c|c|c|c|c|c|c|c|c|c|}
\hline \multirow[b]{2}{*}{ Year } & \multicolumn{3}{|c|}{$\begin{array}{c}\text { (AEX 25) } \\
\text { NETHERLANDS } \\
\end{array}$} & \multicolumn{3}{|c|}{$\begin{array}{l}\text { (ATHEX 20) } \\
\text { GREECE }\end{array}$} & \multicolumn{3}{|c|}{$\begin{array}{r}\text { (ATX 20) } \\
\text { AUSTRIA } \\
\end{array}$} & \multicolumn{3}{|c|}{$\begin{array}{c}\text { (BEL 20) } \\
\text { BELGIUM }\end{array}$} & \multicolumn{3}{|c|}{$\begin{array}{l}\text { (CAC 40) } \\
\text { FRANCE }\end{array}$} \\
\hline & $\mathbf{A S}_{\mathbf{9 0 \%}}$ & $\mathbf{A S}_{\mathbf{9 5} \%}$ & $\mathbf{A S}_{\mathbf{9 9 \%}}$ & $\mathbf{A} \mathbf{S}_{\mathbf{9 0 \%}}$ & $\mathbf{A S}_{\mathbf{9 5} \%}$ & $\mathbf{A S}_{\mathbf{9 9} \%}$ & $\mathbf{A S}_{\mathbf{9 0} \%}$ & $\mathbf{A S}_{\mathbf{9 5} \%}$ & $\mathbf{A S}_{\mathbf{9 9} \%}$ & $\mathbf{A S}_{\mathbf{9 0} \%}$ & $\mathbf{A S}_{\mathbf{9 5} \%}$ & $\mathbf{A S}_{\mathbf{9 9 \%}}$ & $\mathbf{A S}_{\mathbf{9 0} \%}$ & $\mathbf{A S}_{\mathbf{9 5} \%}$ & $\mathbf{A S}_{\mathbf{9 9 \%}}$ \\
\hline 2007 & 24.92 & 26.13 & 28.59 & na & na & na & 28.50 & 31.50 & 36.28 & 27.65 & 29.53 & 32.82 & 16.44 & 17.12 & 18.52 \\
\hline 2008 & 28.66 & 30.25 & 33.17 & na & na & na & 28.63 & 35.71 & 40.64 & 29.91 & 31.17 & 33.95 & 19.04 & 19.67 & 20.93 \\
\hline 2009 & 24.38 & 25.99 & 28.97 & na & na & na & 25.23 & 29.19 & 33.14 & 28.44 & 29.84 & 32.37 & 16.82 & 17.55 & 19.02 \\
\hline 2010 & 24.48 & 25.75 & 28.38 & na & na & na & 23.44 & 26.57 & 29.62 & 24.50 & 26.16 & 29.39 & 16.03 & 16.75 & 18.20 \\
\hline 2011 & 25.49 & 26.53 & 28.64 & 30.03 & 31.66 & 34.02 & 23.41 & 27.06 & 30.74 & 25.27 & 26.78 & 29.82 & 18.41 & 19.14 & 20.48 \\
\hline 2012 & 24.03 & 25.17 & 27.23 & 29.76 & 30.80 & 32.87 & 23.49 & 27.73 & 31.27 & 25.01 & 26.72 & 29.70 & 20.33 & 20.99 & 22.21 \\
\hline 2013 & 21.45 & 22.58 & 24.59 & 28.52 & 29.69 & 31.92 & 26.39 & 30.44 & 34.52 & 24.35 & 25.85 & 28.12 & 16.87 & 17.66 & 20.03 \\
\hline 2014 & 21.73 & 22.82 & 24.38 & 28.37 & 29.80 & 32.41 & 22.63 & 26.48 & 30.08 & 23.85 & 24.88 & 26.81 & 12.99 & 13.77 & 17.67 \\
\hline 2015 & 21.08 & 22.01 & 24.15 & 29.72 & 31.02 & 33.50 & 21.24 & 25.32 & 29.03 & 22.85 & 23.68 & 25.26 & 11.54 & 12.25 & 16.12 \\
\hline 2016 & 19.81 & 20.41 & 21.54 & 29.97 & 31.23 & 33.66 & 19.22 & 22.75 & 26.40 & 23.74 & 24.99 & 27.66 & 11.25 & 11.95 & 15.88 \\
\hline \multirow[t]{2}{*}{ Average } & 23.60 & 24.76 & 26.96 & 29.40 & 30.70 & 33.06 & 24.22 & 28.28 & 32.17 & 25.56 & 26.96 & 29.59 & 15.97 & 16.69 & 18.91 \\
\hline & \multicolumn{3}{|c|}{$\begin{array}{l}\text { (DAX 30) } \\
\text { GERMANY }\end{array}$} & \multicolumn{3}{|c|}{$\begin{array}{c}\text { (FTSE MIB 40) } \\
\text { ITALY } \\
\end{array}$} & \multicolumn{3}{|c|}{$\begin{array}{l}\text { (IBEX 35) } \\
\text { SPAIN }\end{array}$} & \multicolumn{3}{|c|}{$\begin{array}{l}\text { (OMX 25) } \\
\text { FINLAND }\end{array}$} & \multicolumn{3}{|c|}{$\begin{array}{c}\text { (PSI 20) } \\
\text { PORTUGAL }\end{array}$} \\
\hline Year & $\mathbf{A S}_{\mathbf{9 0} \%}$ & $\mathbf{A S}_{\mathbf{9 5} \%}$ & $\mathbf{A S}_{\mathbf{9 9 \%}}$ & $\mathbf{A S}_{\mathbf{9 0} \%}$ & $\mathbf{A S}_{95 \%}$ & $\mathbf{A S}_{99 \%}$ & $\mathbf{A S}_{\mathbf{9 0} \%}$ & $\mathbf{A S}_{\mathbf{9 5} \%}$ & $\mathbf{A S}_{\mathbf{9 9} \%}$ & $\mathbf{A S}_{\mathbf{9 0} \%}$ & $\mathbf{A S}_{95 \%}$ & $\mathbf{A S}_{99 \%}$ & $\mathbf{A S}_{\mathbf{9 0} \%}$ & $\mathbf{A S}_{\mathbf{9 5} \%}$ & $\mathbf{A S}_{\mathbf{9 9} \%}$ \\
\hline 2007 & 15.43 & 16.16 & 17.50 & na & na & na & 25.77 & 27.04 & 28.39 & 22.10 & 23.54 & 26.21 & na & na & na \\
\hline 2008 & 16.72 & 17.42 & 18.79 & na & na & na & 29.80 & 31.13 & 33.04 & 23.56 & 25.00 & 27.74 & na & na & na \\
\hline 2009 & 14.68 & 15.23 & 16.31 & 25.48 & 26.55 & 28.89 & 32.68 & 33.55 & 36.00 & 19.34 & 20.54 & 22.90 & na & na & na \\
\hline 2010 & 14.87 & 15.43 & 16.52 & 23.93 & 24.94 & 27.07 & 32.70 & 33.54 & 35.27 & 15.95 & 17.15 & 19.62 & na & na & na \\
\hline 2011 & 17.33 & 17.96 & 19.20 & 22.68 & 23.62 & 25.30 & 29.36 & 30.41 & 32.00 & 15.38 & 16.11 & 17.63 & na & na & na \\
\hline 2012 & 17.25 & 18.15 & 19.70 & 21.75 & 22.61 & 24.13 & 28.01 & 28.7 & 30.22 & 15.60 & 16.34 & 17.78 & 36.62 & 37.66 & 40.61 \\
\hline 2013 & 17.32 & 18.26 & 20.19 & 20.13 & 21.00 & 22.73 & 26.20 & 26.93 & 28.57 & 13.77 & 14.64 & 16.21 & 32.27 & 32.77 & 34.57 \\
\hline 2014 & 15.33 & 16.29 & 18.42 & 18.16 & 18.94 & 20.55 & 22.24 & 23.03 & 24.57 & 11.75 & 12.34 & 13.70 & 30.41 & 31.50 & 32.81 \\
\hline 2015 & 15.01 & 15.86 & 17.75 & 18.29 & 18.96 & 20.35 & 21.52 & 22.41 & 24.08 & 14.39 & 14.94 & 16.11 & 28.90 & 30.14 & 32.75 \\
\hline 2016 & 15.29 & 15.85 & 17.77 & 20.20 & 20.92 & 22.17 & 18.17 & 19.02 & 20.52 & 15.49 & 16.07 & 17.16 & 29.42 & 30.73 & 33.69 \\
\hline Average & 15.92 & 16.66 & 18.22 & 21.33 & 22.19 & 23.90 & 26.65 & 27.58 & 29.27 & 16.73 & 17.67 & 19.51 & 31.52 & 32.56 & 34.89 \\
\hline
\end{tabular}




\section{Active management in domestic equity funds of the Eurozone}

This section aims to measure the level of active management of the domestic equity funds registered in each Eurozone market. We analyse a comprehensive sample of Eurozone open-end mutual funds categorized as domestic equity funds by Morningstar ${ }^{16}$. We obtain the portfolio holdings, the Total Net Assets (TNA), the domicile and the primary prospectus benchmarks. The sample covers the same period as the previous section, from January 2007 to December 2016. The initial sample drawn from Morningstar consists of 570 domestic equity funds. This sample is free of survivorship bias because it includes both active and terminated funds. To avoid potential heterogeneity problems in the fund sample that could lead to non-comparable AS results, we exclude those equity funds from our initial sample whose primary prospectus benchmarks are not clearly defined or are different from those previously included in our domestic benchmark sample. We also exclude Index funds and other categories (e.g., Funds of Funds) because their investment policy conflicts with the objectives of our analysis ${ }^{17}$.

Our final sample includes 23,749 portfolio holdings from 381 domestic equity funds that have a primary prospectus benchmark included in our domestic benchmark sample. The database used in this analysis relies on monthly portfolio holdings information from January 2007 to December 2016. We work with monthly portfolio holdings when this information is provided and with quarterly portfolio holdings otherwise. Table 4 reports descriptive statistics of our final sample. The most relevant mutual fund industries in the Eurozone, such as France, Germany, Spain and Italy, are also obviously important in our sample. However, the average fund size and the median number of portfolio holdings are assorted across the different Eurozone markets.

Focusing on the original approach of AS by Cremers and Petajisto (2009), we formulate actual active share (aAS) considering the level of concentration existing in the domestic equity funds in the Eurozone markets and the limits of the portfolio concentration on European regulation. We define aAS as the difference between the monthly AS obtained for each domestic equity fund minus its monthly AS-threshold obtained in the previous section at $90 \%, 95 \%$ and $99 \%$ confidence levels. That is, aAS is

\footnotetext{
${ }^{16}$ According to Morningstar, domestic equity funds are defined as funds with at least $70 \%$ of assets invested in domestic stocks.

${ }^{17}$ We analyse $67 \%$ out of all the domestic equity funds registered in the Eurozone domestic fund market during our sample period (Source: Morningstar). Domestic equity funds with a different primary prospectus benchmark (20\%) or an unclear benchmark (7\%) were excluded, as well as Index Funds and Funds of Funds $(6 \%)$.
} 
the level of significant active management over the spurious level driven by the benchmark concentration and the EU concentration limits.

$$
a A S_{90 \%, 95 \%, 99 \%}=A S-A S_{-} \text {Threshold } 90 \%, 95 \%, 99 \%
$$

Table 5 shows the average and the standard deviation values of both AS and aAS in each Eurozone market using the AS-threshold of $95 \%{ }^{18}$. Each value obtained by each fund and period is not sensitive to the number of funds included in each market because these active management measures are individually applied to each fund.

Table 5 provides evidence that aAS significantly corrects the potential bias in the original AS caused by both the benchmark concentration and the EU portfolio diversification rules. This finding is more evident in those markets with the highest AS: the Belgian market, the Greek market and the Portuguese market with AS values of $57.63 \%, 53.43 \%$ and $52 \%$, respectively ${ }^{19}$. These values subside into much lower levels of $\mathrm{aAS}_{95 \%}, 29.62 \%, 22.74 \%$, and $19.45 \%$, respectively.

Further, we find diverse results in the dispersion of both AS and aAS measures. There are markets where domestic equity funds with high values in these active management measures are not distinctively different from other funds with low AS and aAS values. But our novel aAS should not have contradictory performance implications with those obtained by the original AS results (Cremers et al., 2016) because the active management range is constant for both measures in each market and period. ${ }^{20}$

Table 5 shows assorted results and thus the question arises as to whether the level of active management in the Eurozone markets presents significant differences. Using the Kruskal-Wallis test, we test the significance of actual active management in domestic equity funds across 10 different Eurozone markets. We apply the test with the monthly $\mathrm{aAS}_{95 \%}$ from January 2007 to December $2016^{21}$. Table 6 shows conclusive results. There are significant differences in the active management between domestic equity funds in the Eurozone markets at a $1 \%$ confidence level ${ }^{22}$.

We apply the Nemenyi test - comparing markets pairwise - with the aim of detecting which markets are producing the significant differences in the level of active management. Table 6 shows that France, Italy and Spain are the most economically

\footnotetext{
${ }^{18}$ The results are also consistent when we use the threshold of $90 \%$ and the threshold of $99 \%$ developed in the previous section. Detailed results per year are available upon request.

${ }^{19}$ The conclusions about the Belgian market should be taken with caution because the monthly portfolio holdings are very limited.

${ }^{20}$ The only difference between both AS and aAS is the subtraction of the AS-Threshold, which is constant for each domestic benchmark and period.

${ }^{21}$ The monthly aAS $\mathrm{A}_{95 \%}$ used in this analysis has been standardized to compare the results.

${ }^{22}$ The results are also consistent for $\mathrm{aAS}_{90 \%}$ and $\mathrm{aAS}_{99 \%}$. Detailed results are available upon request.
} 
important markets that drive these results. The French market presents significant differences in active management compared with the rest of the domestic equity funds in the Eurozone. The primary implication of this result, together with both the average AS and $\mathrm{aAS}_{95 \%}$ (Table 5), is that domestic equity funds in France are - significantly - the most active in the Eurozone. Next, the Spanish and Italian domestic equity funds present similar active management levels but significant differences with the rest of the Eurozone. Although the Spanish benchmark IBEX 35 obtains a larger spurious AS than does the Italian FTSE MIB 40, the actual levels of active management of Spanish and Italian domestic equity funds are similar through the $\mathrm{aAS}_{95 \%}$ and significantly higher than the rest of the domestic equity funds of the Eurozone, with the exception of French funds.

Similar to the French domestic benchmark, the low levels of concentration of the German DAX 30 should anticipate higher levels of aAS of domestic equity funds in this market. That is, EU diversification rules fulfilled by domestic equity funds registered in Germany should not be in conflict with the well-diversified DAX 30. However, we now have evidence of the contrary. This market does not present significant differences - in terms of active management - from other domestic equity fund industries, whose domestic benchmarks are much more concentrated. Overall, the most economically relevant fund industries in the Eurozone show significant differences in the actual levels of active management. 
Table 4

Domestic equity funds. Summary statistics. This table shows the number of domestic equity funds registered in each Eurozone market and (1) the number of portfolio holdings analysed, (2) the median number of holdings in each mutual fund portfolio, and (3) the average fund size in millions of euros.

\begin{tabular}{|c|c|c|c|c|c|c|c|c|c|c|c|c|c|c|c|}
\hline & \multicolumn{3}{|c|}{ NETHERLANDS } & \multicolumn{3}{|c|}{ GREECE } & \multicolumn{3}{|c|}{ AUSTRIA } & \multicolumn{3}{|c|}{ BELGIUM } & \multicolumn{3}{|c|}{ FRANCE } \\
\hline No. domestic equity funds & \multicolumn{3}{|c|}{11} & \multicolumn{3}{|c|}{13} & \multicolumn{3}{|c|}{10} & \multicolumn{3}{|c|}{6} & \multicolumn{3}{|c|}{150} \\
\hline Year & (1) & (2) & (3) & (1) & (2) & (3) & (1) & (2) & (3) & (1) & (2) & (3) & (1) & (2) & (3) \\
\hline 2007 & 67 & 26 & 406.51 & 65 & 50 & 190.29 & 37 & 50 & 178.31 & 6 & 42 & 30.01 & 298 & 58 & 256.21 \\
\hline 2008 & 61 & 25 & 292.70 & 60 & 45 & 109.47 & 35 & 44 & 111.37 & 19 & 44 & 16.23 & 455 & 51 & 158.67 \\
\hline 2009 & 62 & 27 & 253.90 & 69 & 42 & 68.99 & 56 & 40 & 81.46 & 19 & 51 & 10.75 & 779 & 53 & 156.94 \\
\hline 2010 & 64 & 27 & 482.75 & 60 & 41 & 52.50 & 58 & 41 & 155.08 & 23 & 51 & 20.30 & 731 & 56 & 158.03 \\
\hline 2011 & 73 & 28 & 472.83 & 62 & 35 & 51.00 & 68 & 41 & 143.19 & 13 & 44 & 36.50 & 728 & 55 & 151.70 \\
\hline 2012 & 76 & 27 & 407.41 & 42 & 39 & 37.18 & 66 & 40 & 150.12 & 12 & 55 & 65.23 & 795 & 56 & 138.55 \\
\hline 2013 & 78 & 27 & 407.52 & 44 & 36 & 52.26 & 76 & 35 & 177.48 & 3 & 53 & 69.40 & 841 & 61 & 172.84 \\
\hline 2014 & 61 & 26 & 426.61 & 87 & 42 & 60.89 & 78 & 33 & 181.93 & na & na & na & 902 & 61 & 174.99 \\
\hline 2015 & 48 & 29 & 272.58 & 82 & 41 & 39.63 & 81 & 34 & 197.66 & na & na & na & 895 & 61 & 177.94 \\
\hline 2016 & 51 & 29 & 233.21 & 81 & 39 & 36.08 & 84 & 36 & 219.55 & na & na & na & 972 & 61 & 198.24 \\
\hline \multirow[t]{2}{*}{ Average } & 64 & 27 & 365.60 & 65 & 41 & 69.83 & 64 & 39 & 159.62 & 14 & 49 & 35.49 & 740 & 57 & 174.41 \\
\hline & \multicolumn{3}{|c|}{ GERMANY } & \multicolumn{3}{|c|}{ ITALY } & \multicolumn{3}{|c|}{ SPAIN } & \multicolumn{3}{|c|}{ FINLAND } & \multicolumn{3}{|c|}{ PORTUGAL } \\
\hline No. domestic equity funds & \multicolumn{3}{|c|}{65} & \multicolumn{3}{|c|}{34} & \multicolumn{3}{|c|}{45} & \multicolumn{3}{|c|}{32} & \multicolumn{3}{|c|}{15} \\
\hline Year & (1) & $(2)$ & (3) & (1) & $(2)$ & (3) & (1) & (2) & (3) & (1) & (2) & (3) & (1) & (2) & (3) \\
\hline 2007 & 379 & 56 & 523.83 & 177 & 81 & 207.68 & 220 & 45 & 111.67 & 139 & 38 & 140.68 & 180 & 34 & 78.19 \\
\hline 2008 & 408 & 51 & 346.28 & 219 & 70 & 131.50 & 240 & 38 & 52.82 & 168 & 35 & 84.45 & 180 & 35 & 40.92 \\
\hline 2009 & 455 & 52 & 329.67 & 273 & 66 & 95.78 & 241 & 38 & 35.47 & 191 & 36 & 92.38 & 150 & 34 & 29.64 \\
\hline 2010 & 422 & 56 & 453.39 & 257 & 66 & 101.29 & 296 & 37 & 35.88 & 227 & 36 & 122.08 & 165 & 33 & 29.58 \\
\hline 2011 & 404 & 58 & 571.60 & 251 & 68 & 90.13 & 307 & 36 & 34.81 & 248 & 34 & 120.69 & 165 & 31 & 19.27 \\
\hline 2012 & 418 & 52 & 558.67 & 244 & 69 & 88.08 & 313 & 36 & 30.34 & 268 & 33 & 109.13 & 171 & 32 & 12.38 \\
\hline 2013 & 382 & 48 & 615.32 & 182 & 73 & 117.47 & 371 & 38 & 52.76 & 276 & 34 & 125.72 & 149 & 31 & 16.55 \\
\hline 2014 & 373 & 46 & 698.86 & 190 & 77 & 155.59 & 403 & 42 & 109.36 & 302 & 34 & 130.04 & 143 & 34 & 25.93 \\
\hline 2015 & 389 & 47 & 776.34 & 191 & 80 & 178.63 & 430 & 41 & 115.37 & 251 & 33 & 154.36 & 125 & 31 & 22.51 \\
\hline 2016 & 388 & 48 & 740.70 & 192 & 75 & 155.65 & 452 & 39 & 92.80 & 243 & 34 & 156.79 & 118 & 29 & 18.65 \\
\hline Average & 402 & 51 & 561.47 & 218 & 73 & 132.18 & 327 & 39 & 67.13 & 231 & 35 & 123.63 & 155 & 32 & 29.36 \\
\hline
\end{tabular}


Table 5

Actual active management in domestic equity funds in the Eurozone. This table presents the monthly average AS (in percent terms) proposed by Cremers and Petajisto (2009), the monthly average $\mathrm{aAS}_{95 \%}$ obtained from equation (17) and the monthly average standard deviation of both average $\mathrm{AS}$ and aAS $95 \%$.

\begin{tabular}{|c|c|c|c|c|c|c|c|c|c|c|c|c|c|c|c|}
\hline \multirow[b]{2}{*}{ Year } & \multicolumn{3}{|c|}{ NETHERLANDS } & \multicolumn{3}{|c|}{ GREECE } & \multicolumn{3}{|c|}{ AUSTRIA } & \multicolumn{3}{|c|}{ BELGIUM } & \multicolumn{3}{|c|}{ FRANCE } \\
\hline & AS & $\mathbf{a A S}_{95 \%}$ & St. Dev & AS & $\mathbf{a A S}_{\mathbf{9 5} \%}$ & St. Dev & $\mathbf{A S}$ & $\mathbf{a A S}_{95 \%}$ & St. Dev & AS & $\mathbf{a A S}_{\mathbf{9 5} \%}$ & St. Dev & AS & $\mathbf{a A S}_{95 \%}$ & St. Dev \\
\hline 2007 & 36.80 & 10.67 & 11.91 & na & na & na & 48.72 & 17.22 & 4.17 & 39.75 & 10.22 & 36.85 & 50.68 & 33.56 & 16.44 \\
\hline 2008 & 37.17 & 6.91 & 12.26 & na & na & na & 45.87 & 10.16 & 8.16 & 53.32 & 22.16 & 23.56 & 50.18 & 30.51 & 17.15 \\
\hline 2009 & 33.82 & 7.83 & 12.09 & na & na & na & 52.99 & 23.80 & 5.70 & 54.45 & 24.61 & 12.94 & 47.40 & 29.84 & 18.67 \\
\hline 2010 & 34.13 & 8.38 & 14.48 & na & na & na & 45.94 & 19.37 & 8.34 & 47.08 & 20.91 & 17.95 & 49.23 & 32.48 & 18.34 \\
\hline 2011 & 33.56 & 7.03 & 10.88 & 65.68 & 34.03 & 8.26 & 43.98 & 16.92 & 12.19 & 57.31 & 30.52 & 17.33 & 51.20 & 32.07 & 17.26 \\
\hline 2012 & 36.29 & 11.12 & 11.31 & 62.25 & 31.45 & 6.18 & 41.56 & 13.83 & 10.82 & 74.49 & 47.78 & 24.54 & 51.00 & 30.02 & 17.16 \\
\hline 2013 & 35.55 & 12.97 & 11.91 & 52.29 & 22.60 & 4.50 & 41.64 & 11.20 & 10.00 & 76.99 & 51.13 & 19.01 & 48.15 & 30.49 & 18.15 \\
\hline 2014 & 37.63 & 14.81 & 16.93 & 49.34 & 19.54 & 5.58 & 44.64 & 18.16 & 8.05 & na & na & na & 51.87 & 38.10 & 19.17 \\
\hline 2015 & 51.89 & 29.88 & 16.66 & 46.64 & 15.62 & 8.94 & 48.31 & 22.99 & 10.08 & na & na & na & 53.71 & 41.47 & 19.40 \\
\hline 2016 & 57.69 & 37.28 & 6.81 & 44.40 & 13.17 & 14.95 & 45.25 & 22.50 & 11.71 & na & na & na & 52.91 & 40.96 & 19.76 \\
\hline \multirow[t]{2}{*}{ Average } & 39.45 & 14.69 & 12.53 & 53.43 & 22.74 & 8.07 & 45.89 & 17.62 & 8.92 & 57.63 & 29.62 & 21.74 & 50.63 & 33.95 & 18.15 \\
\hline & \multicolumn{3}{|c|}{ GERMANY } & \multicolumn{3}{|c|}{ ITALY } & \multicolumn{3}{|c|}{ SPAIN } & \multicolumn{3}{|c|}{ FINLAND } & \multicolumn{3}{|c|}{ PORTUGAL } \\
\hline Year & AS & $\mathbf{a A S}_{\mathbf{9 5} \%}$ & St. Dev & AS & $\mathbf{a A S}_{95 \%}$ & St. Dev & AS & $\mathrm{aAS}_{95 \%}$ & St. Dev & AS & $\mathrm{aAS}_{95 \%}$ & St. Dev & $\mathbf{A S}$ & $\mathbf{a A S}_{95 \%}$ & St. Dev \\
\hline 2007 & 30.74 & 14.58 & 12.48 & na & na & na & 46.92 & 19.88 & 9.79 & 42.36 & 18.82 & 17.83 & na & na & na \\
\hline 2008 & 33.88 & 16.46 & 11.89 & na & na & na & 48.47 & 17.35 & 9.41 & 42.43 & 17.43 & 18.39 & na & na & na \\
\hline 2009 & 33.15 & 17.92 & 11.16 & 48.91 & 22.37 & 16.62 & 52.19 & 18.64 & 13.86 & 39.31 & 18.77 & 17.64 & na & na & na \\
\hline 2010 & 32.41 & 16.98 & 15.60 & 51.42 & 26.48 & 17.66 & 54.52 & 20.98 & 12.83 & 39.10 & 21.95 & 18.43 & na & na & na \\
\hline 2011 & 34.25 & 16.29 & 16.24 & 50.91 & 27.29 & 17.48 & 57.17 & 26.76 & 11.74 & 41.19 & 25.09 & 17.96 & na & na & na \\
\hline 2012 & 34.14 & 15.98 & 16.76 & 48.89 & 26.28 & 15.91 & 52.64 & 23.93 & 16.57 & 40.91 & 24.56 & 17.30 & 57.73 & 20.08 & 5.91 \\
\hline 2013 & 31.84 & 13.58 & 13.40 & 47.91 & 26.91 & 16.06 & 51.55 & 24.62 & 14.72 & 40.95 & 26.30 & 16.52 & 54.06 & 21.30 & 5.17 \\
\hline 2014 & 36.43 & 20.15 & 19.32 & 46.17 & 27.24 & 14.91 & 52.64 & 29.61 & 16.20 & 41.03 & 28.69 & 15.72 & 51.38 & 19.88 & 3.74 \\
\hline 2015 & 38.88 & 23.01 & 19.04 & 47.38 & 28.41 & 14.57 & 50.82 & 28.41 & 17.99 & 39.97 & 25.02 & 16.59 & 48.74 & 18.60 & 3.65 \\
\hline 2016 & 42.33 & 26.48 & 18.42 & 47.58 & 26.66 & 14.10 & 50.88 & 31.86 & 20.33 & 41.42 & 25.35 & 14.53 & 48.09 & 17.37 & 3.41 \\
\hline Average & 34.81 & 18.14 & 15.43 & 48.65 & 26.46 & 15.91 & 51.78 & 24.20 & 14.34 & 40.87 & 23.2 & 17.09 & 52.00 & 19.45 & 4.38 \\
\hline
\end{tabular}


Table 6

Differences in $\mathrm{aAS}_{95 \%}$ of domestic equity funds of the Eurozone. As this table shows in column 2, the Kruskal-Wallis test robust chi-squared clustered, p.value reported in parentheses reflects significance at the $10 \%, 5 \%$ and $1 \%$ levels, respectively. Columns 3-11 show the results of the Nemenyi test for each country pairwise in the period $2007-$ 2016. The Nemenyi test is a statistical post hoc test with the aim of finding the groups of data that differ after a statistical test of multiple comparisons. If the result is near one, the active management between each domestic fund industry pairwise is similar; instead, if the result is close to zero, the active management is significantly different.

\begin{tabular}{|c|c|c|c|c|c|c|c|c|c|c|}
\hline & \multirow[b]{2}{*}{ Kruskal Wallis test } & \multicolumn{9}{|c|}{ Nemenyi test } \\
\hline & & NETHERLANDS & GREECE & AUSTRIA & BELGIUM & FRANCE & GERMANY & ITALY & SPAIN & FINLAND \\
\hline NETHERLANDS & $0.578(0.000)$ & - & - & - & - & - & - & - & - & - \\
\hline GREECE & $0.722(0.000)$ & 1.000 & - & - & - & - & - & - & - & - \\
\hline AUSTRIA & $0.538(0.000)$ & 1.000 & 1.000 & - & - & - & - & - & - & - \\
\hline BELGIUM & $1.269(0.000)$ & 0.000 & 0.000 & 0.000 & - & - & - & - & - & - \\
\hline FRANCE & $1.306(0.000)$ & 0.000 & 0.000 & 0.000 & 0.000 & - & - & - & - & - \\
\hline GERMANY & $0.488(0.000)$ & 0.715 & 0.999 & 0.948 & 0.000 & 0.000 & - & - & - & - \\
\hline ITALY & $0.811(0.000)$ & 0.000 & 0.000 & 0.000 & 0.014 & 0.000 & 0.000 & - & - & - \\
\hline SPAIN & $0.888(0.000)$ & 0.000 & 0.000 & 0.000 & 0.012 & 0.000 & 0.000 & 0.824 & - & - \\
\hline FINLAND & $0.422(0.000)$ & 0.515 & 0.774 & 0.227 & 0.000 & 0.000 & 0.473 & 0.000 & 0.000 & - \\
\hline PORTUGAL & $0.625(0.000)$ & 0.996 & 1.000 & 1.000 & 0.000 & 0.000 & 0.999 & 0.000 & 0.000 & 0.659 \\
\hline
\end{tabular}




\section{Conclusions}

This study is the first to examine how both the domestic benchmark concentration and the Directive 2009/65/EC on risk of portfolio diversification may distort the accuracy of the original AS of Cremers and Petajisto (2009) in the Eurozone mutual fund industry. Our unbiased approach has important implications for policymakers and practitioners in terms of identification of an active management map of the Eurozone fund industry.

We develop an algorithm to capture the spurious AS, defined as the minimum AS, which is not a consequence of active decisions made by equity fund managers. The results provide evidence of the unfeasibility to make direct AS comparisons in the Eurozone and lead us to obtain three AS-thresholds per domestic equity benchmark, which are the minimum values of AS needed to confirm that domestic equity funds are significantly active at $90 \%, 95 \%$ and $99 \%$ confidence levels.

Finally, we assess active management in a comprehensive sample of domestic equity funds registered in the Eurozone for the period 2007-2016. To do that, we define actual AS as the measure used to identify significant active management over the spurious AS level driven by the domestic equity benchmark concentration and the EU concentration limits. Our evidence suggests that the level of actual active management in the Eurozone presents significant differences. Focusing on the most relevant fund industries in the Eurozone, we find that France is the most active domestic equity fund market. Followed by the Spanish and Italian markets that show high levels of actual active management despite the large concentration in their domestic benchmarks. Conversely, domestic equity funds registered in Germany show lower levels of active management.

Our findings support the hypothesis that our actual AS measure corrects the potential bias in the original AS caused by both the domestic benchmark concentration and the EU portfolio diversification rules. 


\section{Appendix 1: Detailed explanation of algorithm}

By applying our algorithm, users will obtain domestic Eurozone benchmarks which fulfil the portfolio concentration limits of the Directive 2009/65/EC. In our study, the algorithm was applied on a monthly basis. (Figures in parentheses relate to equations of the algorithm included in the main body of the paper.)

Input: The weights of the constituents that are part of each domestic Eurozone benchmark.

Output: The weights of the constituents that are part of each domestic Eurozone benchmark fulfilling the limits of portfolio concentration of the Directive 2009/65/EC.

\section{Terms}

First: The weight of each constituent, called $w_{i}$, is positive, and the sum of their weights for each benchmark is $100 \%$.

Second: Limits of portfolio concentration showed in article 52 on the Directive 2009/65/EC sort $w_{i}$ into three groups.

$$
\begin{aligned}
& \text { Group 1) Include constituents with } w_{i}>10 \% \\
& \text { Group 2) Include constituents with } 5 \% \leq w_{i} \leq 10 \% \\
& \text { Group 3) Include constituents with } w_{i}<5 \%
\end{aligned}
$$

Third: The sum of the weights of the constituents included in Group 1 and Group 2 shall not exceed $40 \%$.

Fourth: The list of the weights of the constituents is arranged from the highest to the lowest.

\section{Process}

1. Initialise the process with Group 1: Reduce weights of its constituents from their original weights to $10 \%$.

2. Consider jointly the recalculated weights of the constituents of Group 1 (step 1) and the original weights of the constituents of Group 2 and obtain the sum of both groups, constituent by constituent (from the highest to the lowest). If the sum is greater than $40 \%$, then reduce the weights of the constituents in Group 2 from their original weights to $5 \%$.

3. Include Group 3 in the process: Define $w$ as the sum of the accumulated weights obtained in step 1 , step 2 and the accumulated weights of the constituents in Group 3. 
4. $\quad$ Define sAS as the difference between $100 \%$ minus $w$

$s A S=100 \%-w$

5. Distribute sAS among the constituents that can incorporate an additional weight following the restrictions included in Terms and proportionally to their original weights.

When the proportional increase leads the new weight of a constituent included in Group 2 to exceed the $10 \%$ limit then the process should be initialised in step 1 with the recalculated weights.

When the proportional increase leads the new weight of a constituent included in Group 3 to exceed the $5 \%$ limit then the process should be initialised in step 2 with the recalculated weights.

6. Obtain the sum of the accumulated weights of the constituents in Group 1 (step 1), Group 2 (step 2) and Group 3 (step 5), constituent by constituent (from the highest to the lowest).

While sAS is higher than zero, continue the proportional distribution described in step 5.

When sAS is equal to zero, the process concludes. 


\section{References}

Ang, A., Madhavan, A., \& Sobczyk, A. (2017). Estimating Time-Varying Factor Exposures. Financial Analysts Journal, 73(4), 41-54. https://doi.org/10.2139/ssrn.2879071

Benink, H. A., Schmidt, \& R. H. (2004). Europe's single market for financial services: views by the European Shadow Financial Regulatory Committee. Journal of Financial stability, 1(2), 157-198. https://doi.org/10.1016/j.jfs.2004.09.008

Bollen, N. P., \& Busse, J. A. (2004). Short-term persistence in mutual fund performance. The Review of Financial Studies, 18(2), 569-597. https://doi.org/10.1093/rfs/hhi007

Bolsa de Madrid 2019. IBEX 35 Factsheet.

http://www.bolsamadrid.es/docs/SBolsas/InformesSB/FS-Ibex35_ESP.pdf (accessed December 2018)

Carhart, M.M. (1997). On persistence in mutual fund performance. The Journal of Finance, 52(1), 57-82. https://doi.org/10.1111/j.1540-6261.1997.tb03808.x

Casavecchia, L., \& Hulley, H. (2018). Are mutual fund investors paying for noise? International Review of Financial Analysis, 58, 8-23. https://doi.org/10.1016/j.irfa.2018.04.002

Clare, A., Motson, N., Sapuric, S., \& Todorovic, N. (2014). What impact does a change of fund manager have on mutual fund performance? International Review of Financial Analysis, 35, 167-177. http://dx.doi.org/10.1016/j.irfa.2014.08.005

Council Directive 85/611/EEC of the European parliament of 20 December 1985 on the coordination of laws, regulations and administrative provisions relating to undertakings for collective investment in transferable securities (UCITS).

Council Directive 2009/65/EC of the European parliament of 13 July 2009 on the coordination of laws, regulations and administrative provisions relating to undertakings for collective investment in transferable securities (UCITS).

Cremers, K. J. M., \& Petajisto, A. (2009). How Active Is Your Fund Manager? A New Measure That Predicts Performance. Review of Financial Studies, 22(9), 3329-3365. https://doi.org/10.1093/rfs/hhp057

Cremers, K.J.M., Ferreira, M. A., Matos, P., \& Starks, L. (2016). Indexing and active fund management: International evidence. Journal of Financial Economics, 120(3), 539-560. https://doi.org/10.1016/j.jfineco.2016.02.008 
Cremers, K.J.M., \& Pareek, A. (2016). Patient capital outperformance: The investment skill of high active share managers who trade infrequently. Journal of Financial Economics, 122(2), 288-306. https://doi.org/10.1016/j.jfineco.2016.08.003

Cremers, K. J. M. (2017). Active Share and the Three Pillars of Active Management:

Skill, Conviction, and Opportunity. Financial Analysts Journal, 73(2), 61-79.

https://doi.org/10.2469/faj.v73.n2.4

Cumming, D., Groh, A. P., \& Johan, S. (2018). Same rules, different enforcement: Market abuse in Europe. Journal of International Financial Markets, Institutions and Money, 54, 130-151. https://doi.org/10.1016/j.intfin.2018.03.006

Daniel, K., Grinblatt, M., Titman, S., \& Wermers, R. (1997). Measuring mutual fund performance with characteristic-based benchmarks. The Journal of Finance, 52(3), 1035-1058. https://doi.org/10.1111/j.1540-6261.1997.tb02724.X

Elton, E. J., Gruber, M. J., \& Blake, C. R. (1996). The persistence of risk-adjusted mutual fund performance. Journal of Business, 69(2) 133-157. https://doi.org/10.1086/209685

European Fund and Asset Management Association (EFAMA), 2017. International Statistical Release. (Annual Report 2017).

https://www.efama.org/Publications/Public/Annual\%20Reports/EFAMAAnnualReport20 17.pdf, (accessed December 2018)

European Fund and Asset Management Association (EFAMA), 2018. International Statistical Release. (Fourth Quarter of 2018).

https://www.efama.org/Publications/Statistics/International/Quarterly\%20\%20Internation al/190327_International\%20Statistical\%20Release\%20Q4\%202018.pdf, （accessed December 2018)

Euronext 2019. CAC 40 Factsheet.

https://www.euronext.com/en/products/indices/FR0003500008-XPAR/marketinformation, (accessed December 2018).

Fama, E. F., \& French, K. R. (1993). Common risk-factors in the returns on stocks and bonds. Journal of Financial Economics, 33(1), 3-56. https://doi.org/10.1016/0304$\underline{405 x(93) 90023-5}$

Fama, E. F., \& French, K. R. (2010). Luck versus Skill in the Cross-Section of Mutual Fund Returns. Journal of Finance, 65(5), 1915-1947. https://doi.org/10.1111/j.1540$\underline{6261.2010 .01598 . x}$

Frazzini, A., Friedman, \& J., Pomorski, L. (2016). Deactivating Active Share. Financial Analysts Journal, 72(2), 14-21. https://doi.org/10.2469/faj.v72.n2.2 
French, K. R. (2008). Presidential address: The cost of active investing. The Journal of Finance, 63(4), 1537-1573. https://doi.org/10.1111/j.1540-6261.2008.01368.x

Frijns, B., \& Indriawan, I. (2018). On the ability of New Zealand actively managed funds to generate outperformance in their domestic equity allocations. Pacific Accounting Review, 30(4), 463-481. https://doi.org/10.1108/par-10-2017-0079

Grinblatt, M., \& Titman, S. (1989). Mutual fund performance: An analysis of quarterly portfolio holdings. Journal of Business, 62(3). 393-416. https://doi.org/10.1086/296468

Grinblatt, M., \& Titman, S. (1993). Performance measurement without benchmarks: An examination of mutual fund returns. Journal of Business, 66(1), 47-68. https://doi.org/10.1086/296593

Huang, J., Sialm, C., \& Zhang, H. J. (2011). Risk shifting and mutual fund performance. The Review of Financial Studies, 24(8), 2575-2616. https://doi.org/10.1093/rfs/hhr001 Jensen, M. C. (1968). The performance of mutual funds in the period 1945-1964. The Journal of Finance, 23(2), 389-416. https://doi.org/10.1111/j.1540$\underline{6261.1968 . t b 00815 . x}$

Jiang, H., Verbeek, M., \& Wang, Y. (2014). Information content when mutual funds deviate from benchmarks. Management Science, 60(8), 2038-2053. https://doi.org/10.1287/mnsc.2013.1847

Lee, S., \& Morri, G. (2015). Real estate fund active management. Journal of Property Investment \& Finance, 33(6), 494-516. https://doi.org/10.1108/jpif-06-2014-0043

Muller, C., \& Ward, M. (2011). Active share on the JSE. Investment Analysts Journal, 40(74), 19-28. https://doi.org/10.1080/10293523.2011.11082538

Muller, S., \& Weber, M. (2012). Evaluating the Rating of Stiftung Warentest: How Good Are Mutual Fund Ratings and Can They Be Improved?. European Financial Management, 20(2), 207-235. https://doi.org/10.1111/j.1468-036X.2011.00632.x

Petajisto, A. (2013). Active Share and Mutual Fund Performance. Financial Analysts Journal, 69(4), 73-93. https://doi.org/10.2469/faj.v69.n4.7

Petajisto, A. (2016). Author Response to "Deactivating Active Share". Financial Analysts Journal,72(4), 11-12. https://doi.org/10.2469/faj.v72.n4.2

Rudolf, M., Wolter, H. J., \& Zimmermann, H. (1999). A linear model for tracking error minimization. Journal of Banking \& Finance, 23(1), 85-103. https://doi.org/10.1016/S0378-4266(98)00076-4 
Schlanger, T., Philips, C. B., \& LaBarge, K. P. (2012). The Search for Outperformance: Evaluating 'Active Share.' Vanguard Research Documents (May), 1-15.

Sharpe, W. F. (1966). Mutual fund performance. Journal of Business, 39(1), 119-138. https://doi.org/10.1086/294846

Sensoy, B. A. (2009). Performance evaluation and self-designated benchmark indexes in the mutual fund industry. Journal of Financial Economics, 92(1), 25-39.

S\&P Dow Jones Indexes 2019. S\&P 500 Factsheet

https://us.spindices.com/idsenhancedfactsheet/file.pdf?calcFrequency=M\&force_downlo $\underline{\mathrm{ad}=\text { true } \& \text { hostIdentifier }=48190 \mathrm{c} 8 \mathrm{c}-42 \mathrm{c} 4-46 \mathrm{af}-8 \mathrm{~d} 1 \mathrm{a}-0 \mathrm{~cd} 5 \mathrm{db} 894797 \& \text { index } \mathrm{Id}=340}$ (accessed December 2018).

Wermers, R. (2000). Mutual fund performance: An empirical decomposition into stockpicking talent, style, transactions costs, and expenses. The Journal of Finance, 55(4), 1655-1695. https://doi.org/10.1111/0022-1082.00263 